\title{
Incidence and Factors Associated with Drug Related Hospital Admissions in a South Indian Tertiary Care Hospital
}

\author{
Sravya Gethika Dammalapati ${ }^{1}$, Siva Reddy Challa ${ }^{*}$, Prasad Challa ${ }^{1}$, Mohammed Irfan $^{1}$, \\ Kavitha Chanumolu', Ravindra Babu Pingili ${ }^{2}$, Krishna Sri Nalla ${ }^{2}$, Eswar G $^{3}$ \\ ${ }^{1}$ Department of Pharmacy Practice, KVSR Siddhartha College of Pharmaceutical Sciences, Vijayawada, Andhra Pradesh, INDIA. \\ ${ }^{2}$ Department of Pharmacology, KVSR Siddhartha College of Pharmaceutical Sciences, Vijayawada, Andhra Pradesh, INDIA. \\ ${ }^{3}$ Department of General Medicine, Dr. Pinnamaneni Siddhartha Institute of Medical Sciences and Research Foundation Chinoutpalli, \\ Gannavaram, Krishna, Andhra Pradesh, INDIA.
}

\begin{abstract}
Objective: The study aimed to assess the incidence, nature of drug related hospital admissions (DRHAs) and factors associated with DRHAs. Method: A retrospective study was conducted to evaluate the medical records of patients admitted to general medicine department for six months. Drug related hospital admissions were assessed using Helper and Stand Classification. Crude odds ratio (COR) and adjusted odds ratio (AOR) were determined using univariate and multivariate logistic regression analysis. Results: The results of analysis of 1177 medical records reveal that 202 (17.2\%) patients were admitted due to 248 DRHAs. Of which, the most common DRHA was non-compliance that accounted for $50.50 \%$ (102). Out of 248 drug related hospital admissions, $65.8 \%$ $(n=163)$ were definitely preventable, $30.2 \% \quad(n=75)$ were possibly preventable and $4.0 \%(n=10)$ were definitely not preventable. However, multivariate regression analysis results indicate that hypertension, diabetes mellitus, and polypharmacy at admission are significantly $(p<0.001)$ associated with DRHA. Conclusion: The factors remarkably associated with drug related hospital admissions are age, diabetes mellitus, hypertension and polypharmacy. The major reasons for drug related hospital admissions are non-compliance and adverse drug reactions. Collaborative efforts among patients, physicians, pharmacists and caregivers might reduce the frequency of drug related hospital admissions.
\end{abstract}

Key words: Drug related hospital admissions, Adverse drug reactions, Compliance, Retrospective study, Risk factors.

\section{INTRODUCTION}

A drug related problem (DRP) is defined as an event or circumstance that involves a patient's drug treatment that actually, or potentially, interferes with the achievement of an optimal outcome. ${ }^{1,2}$ Optimal therapeutic outcome has been defined as an absence of drug related problems (DRPs)., ${ }^{3,4}$ Over the past 40 years, advances in drug therapies have both improved patient care and led to an apparent increase in the incidence of drug related problems being reported. Unresolved DRPs may manifest as drug- related morbidity, which has been described as the phenomenon of therapeutic malfunction or miscarriage or the failure of a therapeutic agent to produce the intended outcome. If left untreated, drug-related morbidity may eventually result in drug related mortality. There is a substantial body of literature that suggests a large proportion of drug-related morbidity is preventable. The cost of drug-related morbidity and mortality in the ambulatory setting is considerable and should be considered in
DOI: 10.5530/ijopp.11.1.7

Address for correspondence: Dr. Siva Reddy Challa, M.Pharm, Ph.D,

Professor and HOD, Department of Pharmacology KVSR Siddhartha College of Pharmaceutical Sciences, Pinnamaneni Poly Clinic Road, Siddhartha Nagar, Vijayawada-520010, Andhra Pradesh, INDIA. Cell No: +918008593009 , Tel: +91-8662479775. Fax: 08662476086 Email Id: sivareddypharma@ gmail.com

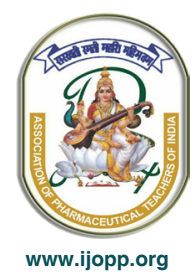


health policy decisions with regard to pharmaceutical benefits. In addition, the reports from groups including the Boston Collaborative Drug Surveillance program indicated that these initial studies put the frequency of such hospital admissions as $1.8-6.2 \% .^{5}$

The primary objective of the study was to assess the incidence and factors associated with drug related hospital admissions in a tertiary care hospital. The secondary objective to assess preventability and severity of drug related hospital admission.

\section{MATERIALS AND METHODS}

\section{Study design}

A retrospective study was carried out in Dr. Pinnamaneni Siddhartha Institute of Medical Sciences and Research Foundation (Dr.PSIMS and RF) at Chinaoutpalli, Gannavaram Mandal, Krishna district, Andhra Pradesh. The medical records of patients admitted to Dr.PSIMS and RF during July 2015-December 2015 (Study duration was 6 months) were reviewed and analysed.

Inclusion criteria: (i) Medical records of the patients with age $>18$ years old. (ii) Medical records of patients who admitted into general medicine ward as inpatient in the study duration were included in the study.

Exclusion criteria: (i) Medical records of the patients, who were hospitalized $<24$ hours. (ii) Incomplete medical records, (iii) Accidental and intentional poisoning medical records (iv) Medical records of patients admitted to paediatrics (v) Patients who are left against medical advice.

\section{Method of data collection}

All the necessary data including the patient demographic details, disease history, allergic status, diagnosis, treatment chart, case notes and data on laboratory investigations were collected from data sources like patient case reports, laboratory reports and documented in a suitably designed data collection form for the study. All the recorded data was reviewed independently by two reviewers to identify DRPs.

\section{Primary and secondary outcomes measures}

Primary outcome measure includes incidence and risk factors associated with medication related hospital admissions while secondary outcome measures were preventability and severity

\section{Statistical analysis}

Statistical analysis was carried out using Graph Pad Prism Version 5.0 and Epi Info 7 software. Continuous variables were presented as Mean \pm Standard deviation (mean $\pm \mathrm{SD}$ ), and categorical variables were reported as frequency and percentage with 95\% confidence intervals. Mann-Whitney test was used to compare the continuous data, and Chi square test was performed for the comparison of categorical data. Independent predictors of drug related hospitalization were identified using a logistic regression analysis, which was adjusted for age, sex, and any other variables that were significant. All analyses were two sided, with $\mathrm{p}$ value of less than or equal to 0.05 considered statistically significant.

\section{Definitions of drug related hospital admission and drug related problems}

Drug related hospital admission-Admission caused by any undesirable clinical manifestation that is consequent to and caused by the administration of a particular drug. The clinical manifestation may be a clinical sign, symptom, or abnormal laboratory test or it may be a cluster of abnormal signs, symptoms, or tests. ${ }^{6,7}$ Hospitalization was defined as drug related if it was directly related to one of eight predefined classifications: adverse drug reaction, drug interaction, improper drug selection, untreated indication, sub-therapeutic dosage, supratherapeutic dosage, non-compliance, and drug use without indication. ${ }^{2,8}$ Adverse drug events unrelated to a patient's chief complaint were not considered as the cause of hospitalization. We used the WHO's definition of adverse drug reaction and included all reactions to drugs administered at appropriate dosages, as well as those associated with abnormal drug concentrations or laboratory values. All other terms were defined using the Hepler and Strand Classification., ${ }^{2,8}$ Improper drug selection: any noxious, unintended, or undesired effect due to the use of a drug not optimal in the treatment of a confirmed indication. Non-compliance: any noxious, unintended, or undesired effect caused by failure to receive a drug. This definition included both patient and physician noncompliance. Supra-therapeutic dosage: any noxious, unintended, or undesired effect caused byexcessive drug dosage or duration for a given indication or patient. Sub-therapeutic dosage: any noxious, unintended, or undesired effect caused by failure to receive sufficient drug dosage or duration for a given indication or patient. Untreated indication: any noxious, unintended, or undesired effect resulting from the failure to treat a known indication. Drug interaction: any noxious, unintended, or undesired effect caused by the co-administration of two or more drugs. Drug use without an indication: any noxious, unintended, or undesired effect caused by the use of a drug for which there is no clear indication. ${ }^{2,8}$

\section{Assessment of preventability}

DRPs were defined as 'definitely preventable' if the patient (i) did not take a drug that is known to reduce 


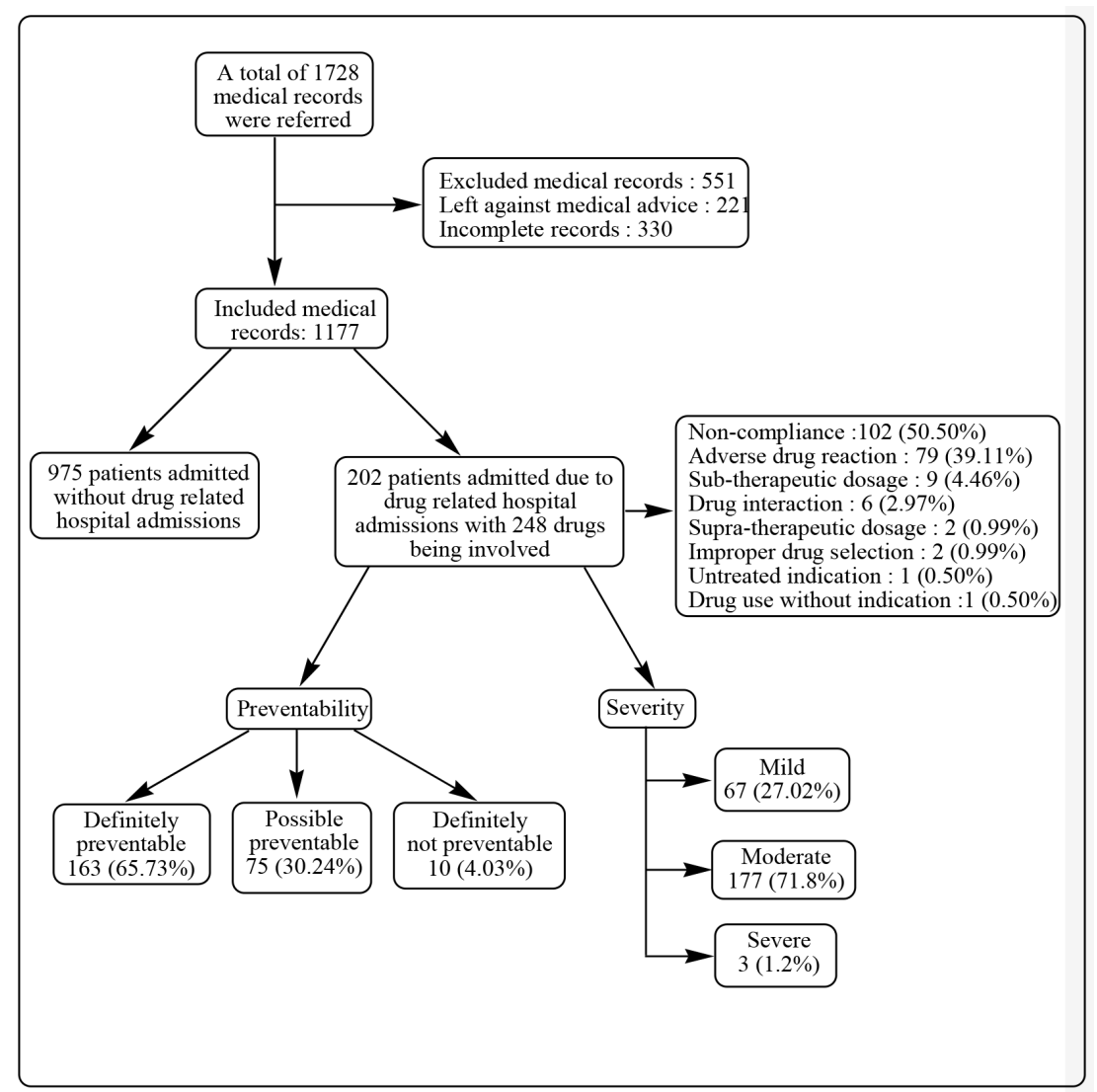

Figure 1: A flow chart represents study design and summary of results.

Table 1: Patient characteristics and comparison between DRHA and Non-DRHA.

\begin{tabular}{|c|c|c|c|}
\hline Variables & DRHA & Non-DRHA & P-value \\
\hline $\begin{array}{l}\text { Total number } \\
\text { of hospital } \\
\text { admissions }\end{array}$ & 202 & 975 & \\
\hline $\begin{array}{l}\text { Total number } \\
\text { of drug being } \\
\text { involved } \\
\text { for hospital } \\
\text { admissions }\end{array}$ & 248 & - & \\
\hline \multicolumn{4}{|c|}{ Gender, N (\%) (\% frequency) } \\
\hline Male & $94(46.5 \%)$ & $453(46.4 \%)$ & 0.9849 \\
\hline Female & $108(53.4 \%)$ & $522(53.5 \%)$ & \\
\hline $\begin{array}{l}\text { Age (years), } \\
\text { (mean } \pm S . D)\end{array}$ & $55.62 \pm 15.7$ & $44.86 \pm 16.79^{*}$ & $<0.001$ \\
\hline $\begin{array}{l}\text { Polypharmacy } \\
\text { at admission } \\
\text { (mean } \pm \text { S.D) }\end{array}$ & $9.49 \pm 4.22$ & $7.011 \pm 3.35^{*}$ & $<0.001$ \\
\hline $\begin{array}{l}\text { Length of } \\
\text { in-hospital stay } \\
\text { (days) (mean } \\
\pm \text { S.D) }\end{array}$ & $6.207 \pm 3.71$ & $5.98 \pm 4.31^{\mathrm{NS}}$ & 0.1735 \\
\hline
\end{tabular}

* $p<0.001$ compared to DRHA group and data is analyzed by Mann-Whitney test. DRHA- drug related hospital admission; Non-DRHA, Non-drug related hospital admission.

Indian Journal of Pharmacy Practice, Vol 11, Issue 1, Jan-Mar, 2018

\section{Table 2: Frequency distribution of DRHAs.}

\begin{tabular}{ccc}
$\begin{array}{c}\text { Type of drug related } \\
\text { hospital admission } \\
\text { (DRHA) }\end{array}$ & $\begin{array}{c}\text { Frequency } \\
\text { (\%) }\end{array}$ & $\begin{array}{c}\text { 95\% confidence } \\
\text { interval (Cl) }\end{array}$ \\
\hline Noncompliance & $102(50.50)$ & $43.39-57.59$ \\
Adverse drug reactions & $79(39.11)$ & $32.34-46.21$ \\
Sub-therapeutic dosage & $9(4.46)$ & $2.06-8.29$ \\
Drug interaction & $6(2.97)$ & $1.10-6.35$ \\
Supra-therapeutic dosage & $2(0.99)$ & $0.12-3.53$ \\
Improper drug selection & $2(0.99)$ & $0.12-3.53$ \\
Untreated indication & $1(0.50)$ & $0.01-2.73$ \\
Drug use without indication & $1(0.50)$ & $0.01-2.73$ \\
\hline
\end{tabular}

DRHA- drug related hospital admission.

Of 248 DRHAs, $65.8 \%$ of definitely preventable, $30.2 \%$ of possibly preventable and $4.0 \%$ of definitely not preventable. Definitely preventable DRHAs commonly are non-compliance and sub-therapeutic dosage. The patients accounted for severity of DRHAs were mild $(27.0 \%)$, moderate $(71.8 \%)$ and severe $(1.2 \%)$. Moderate DRHAs commonly are non-compliance and adverse drug reaction (Table 3, Figure 1).

or prevent the symptoms according to the prescribed directions, (ii) had a known allergy, (iii) had a disease for which the drug was contraindicated, and (iv) took a drug that was not indicated, and possibly avoidable if there is a failure to monitor by a physician at reasonable time 


\begin{tabular}{cccc}
\multicolumn{4}{c}{ Table 3: Frequency distribution of DRHA's preventability and severity. } \\
\hline Preventability & Frequency & Percent & 95\% Confidence interval (C.I) \\
\hline Definitely preventable & 163 & $65.73 \%$ & $59.46-71.61$ \\
Definitely not preventable & 10 & $4.03 \%$ & $1.95-7.29$ \\
Possible preventable & 75 & $30.24 \%$ & $24.59-36.37$ \\
Total & 248 & $100 \%$ & \\
\hline Severity & Frequency & Percent & $\mathbf{9 5 \%}$ Confidence interval (C.I) \\
\hline Mild & 67 & $27.0 \%$ & $33.00-21.59$ \\
Moderate & 178 & $71.8 \%$ & $76.91-65.31$ \\
Severe & 3 & $1.2 \%$ & $4.08-0.44$ \\
Total & 248 & $100 \%$ & \\
\hline
\end{tabular}

DRHA- drug related hospital.

Univariate analysis results indicate that age, hypertension, diabetes mellitus and polypharmacy on admission aresignificantly $(p<0.001)$ associated with the occurrence of DRHA. However, in the multivariate regression analysis reveals that hypertension, diabetes mellitus and polypharmacy on admission are significantly $(p<0.001)$ associated with DRHA occurrence (Table 4).

Table 4: Comparison of univariate analysis and multivariate logistic regression to identify association between DRHA and potential variables.

\begin{tabular}{|c|c|c|c|c|c|c|c|c|}
\hline \multirow[b]{2}{*}{ Variables } & \multirow[b]{2}{*}{ DRHA } & \multirow[b]{2}{*}{ Non-DRHA } & \multicolumn{3}{|c|}{ Univariate analysis } & \multicolumn{3}{|c|}{ Multivariate Logistic regression } \\
\hline & & & C.OR & $\begin{array}{c}95 \% \\
\text { confidence } \\
\text { interval }\end{array}$ & P-value & Adj.OR & $\begin{array}{c}95 \% \\
\text { confidence } \\
\text { interval }\end{array}$ & P-value \\
\hline \multicolumn{9}{|l|}{ Gender } \\
\hline Male & $94(46.53 \%)$ & $453(46.46 \%)$ & & & & & & \\
\hline Female & $108(53.47 \%)$ & $522(53.54 \%)$ & 1.003 & $0.7401-1.359$ & 0.9849 & 0.9220 & $0.6211-0.9220$ & 0.6869 \\
\hline \multicolumn{9}{|l|}{ Age } \\
\hline$\geq 65$ years & $62(30.7 \%)$ & $158(16.21 \%)$ & & & & & & \\
\hline$<65$ years & $140(69.3 \%)$ & $817(83.89 \%)$ & 2.290 & $1.623-3.231$ & $<0.001^{*}$ & 1.1470 & $0.7675-1.7143$ & 0.5034 \\
\hline \multicolumn{9}{|c|}{ Hypertension } \\
\hline Yes & $130(64.36 \%)$ & $167(17.15 \%)$ & & & & & & \\
\hline No & $72(35.64 \%)$ & $807(82.85 \%)$ & 8.725 & $6.255-12.17$ & $<0.001^{*}$ & 4.9332 & $3.4063-7.1435$ & $<0.001^{* *}$ \\
\hline \multicolumn{9}{|c|}{ Diabetes mellitus } \\
\hline Yes & $108(53.47 \%)$ & $155(15.90 \%)$ & & & & & & \\
\hline No & $94(46.53 \%)$ & $820(84.10 \%)$ & 6.078 & $4.389-8.417$ & $<0.001^{*}$ & 2.3538 & $1.6194-3.4211$ & $<0.001^{* *}$ \\
\hline \multicolumn{9}{|c|}{ Smoking habit } \\
\hline Yes & $46(22.77 \%)$ & $153(15.69 \%)$ & & & & & & \\
\hline No & $156(77.23 \%)$ & $822(84.31 \%)$ & 1.584 & $1.09-2.29$ & 0.0145 & 1.1233 & $0.5653-2.2320$ & 0.74 \\
\hline \multicolumn{9}{|c|}{ Alcohol consumption } \\
\hline Yes & $39(19.31 \%)$ & $149(15.28 \%)$ & & & & & & \\
\hline No & $163(80.69 \%)$ & $826(84.72 \%)$ & 1.326 & $0.89-1.96$ & 0.1553 & 1.0624 & $0.5264-2.1442$ & 0.8657 \\
\hline \multicolumn{9}{|c|}{$\begin{array}{l}\text { Polypharmacy at } \\
\text { admission }\end{array}$} \\
\hline$\geq 12$ & $70(34.65 \%)$ & $83(8.51 \%)$ & & & & & & \\
\hline$<12$ & $132(65.35 \%)$ & 892(91.49\%) & 5.952 & $4.130-8.578$ & $<0.001^{*}$ & 3.5102 & $2.2990-5.3594$ & $<0.001^{* *}$ \\
\hline \multicolumn{9}{|c|}{$\begin{array}{l}\text { Length of in-hospital } \\
\text { stay(days) }\end{array}$} \\
\hline$\geq 10$ & $38(18.81 \%)$ & $127(13.04 \%)$ & & & & & & \\
\hline$<10$ & $164(81.19 \%)$ & $847(86.96 \%)$ & 1.545 & $1.037-2.304$ & 0.0316 & 1.6336 & $1.0431-2.5582$ & 0.0320 \\
\hline
\end{tabular}

OR: Crude Odds ratio; Adj.OR: Adjusted Odds ratio; * $\mathrm{p}<0.001$ compared to non-DRHA group analyzed by Chi square test (univariate analysis) and **p< 0.001 compared to non-DRHA group analyzed by multivariate logistic regression analysis; DRHA: Drug related hospital admission 
intervals and inadequate monitoring due to inability to see a physician (e.g., financial difficulties). ${ }^{9}$

\section{Assessment of severity}

Severity of hospitalization was defined as mild (laboratory abnormalities or symptoms not requiring treatment), moderate (laboratory abnormalities or symptoms requiring treatment or resulting in non-permanent disability), severe (life threatening or resulting in permanent disability), or fatal. ${ }^{6,10,11}$

\section{RESULTS}

A total of 1728 medical records were collected and analysed. Out of which, 1177 medical records were included in the study. During the study period, a total of 1177 patients were admitted to general medicine ward. Of which, $202(17.2 \%)$ patients were admitted due to drug related hospital admissions with 248 drugs being involved and remaining $975(88.3 \%)$ patients were admitted without drug related hospital admissions. Out of 202 patients admitted to the hospital due to DRHA, $53.4 \%$ were females while $46.5 \%$ were males. Out of 975 patients of non-DRHA, $522(53.5 \%)$ were females whereas $453(44.4 \%)$ of patients were males (Table 1, Figure 1).

The drug related hospital admission was classified into non-compliance, adverse drug reaction, drug interaction, sub-therapeutic dosage, supra-therapeutic dosage, improper drug selection, untreated indication and drug use without indication. The most common DRHAs was due to non-compliance $(50.5 \%)$ and adverse drug reactions (ADRs) (39.11\%). The data was shown in Table 2.

\section{DISCUSSION}

\section{Drug related hospital admissions}

Our study results revealed that $17.2 \%$ (202) patients were admitted due to drug related problems with 248 drugs being involved. Our results are in accordance with previous findings of prospective study in which approximately $10-28 \%$ of emergency department visits were due to DRPs but retrospective studies identified them in the range of $0.86-10.6 \% .^{12,13,14,15}$ This considerable variation in the incidence of drug-related visits to hospital emergency room is due to variable objectives, definitions and methods applied to the studies. ${ }^{15,16}$

\section{Causes of drug related hospital admissions}

Our data implied that highest numbers of drug related hospital admissions are majorly attributed to non-compliance $(50.50 \%)$ and adverse drug reactions (39.11\%). Our results are also in consistent with the previous findings that stated adverse drug reactions and non- compliance are the primary reasons for drug-related morbidity, regardless of study setting.

\section{Non-compliance}

A collaborative and interdisciplinary patient care model is most beneficial in providing safe and effective therapy. ${ }^{17}$ Among all DRP related admissions, non-compliance was the foremost and account for $50.5 \%$ of total admissions. The major reason is that most of patient population belonging to rural area and they are illiterate with low economic status. Complicated medication regimens and inability to recall the regimen and the greater number of preparations used were other important reasons associated with increased risk of non-compliance and increased risk of a hospitalization related to non-compliance. The higher rates of noncompliance in our set-up, particularly in young adults, are alarming. Our result is in consistent with previous findings. ${ }^{18}$

\section{Adverse drug reactions}

Most of the hospital admissions possibly arising from ADRs that are detected in the present study are associated with cardiovascular drugs. This finding was supported by previous results. ${ }^{19}$ Our study results also revealed that oral hypoglycemics are the second categories of drugs that have caused ADR related hospital admission. Larger number of diabetic patients in our study population and poor awareness of patients with regard to hypoglycaemic symptoms might be plausible explanation for increased ADRs observed with oral hypoglycaemic drugs. In addition, some of diabetic patients admitted due to corticosteroid induced hyperglycaemia. Our results are supported by previous findings where in corticosteroid induced hyperglycaemia. ${ }^{20}$ Interestingly, patient was taken IV contrast media when he was on metformin that is contraindicated in IV contrast media administered patient. Similar results were observed in earlier study. ${ }^{21}$ Therefore; patients who are on oral hypoglycaemic and insulin therapy should be included and prioritized in pharmaceutical care services to assess the safety of the treatment and to decrease the prevalence of hospitalizations due to DRPs. Another meta-analysis of Australian studies published from 1988 to 1996 reported that the most commonly implicated drug groups were cytotoxic drugs, cardiovascular agents, anticoagulants and nonsteroidal anti-inflammatory drugs ${ }^{22}$ whereas other study reports indicated that anti-thrombotic accounted for the highest incidence $(0.24 \%)$ of drug related admissions. ${ }^{23}$ On the contrary to our findings, a previous study results also revealed that thiazide diuretics were identified as contributors of hyponatremia whereas anti-arrhythmic drugs contributed to toxicities. Almost similar result was found in another study wherein CVS drugs contributed to $18.3 \%$ of the emergency visits. ${ }^{15}$ Dartnell et al. 
found that $5.7 \%$ of emergency admissions to hospital over a period of 1 month were drug-related, with 83 drugs being implicated. Over $30 \%$ of these medications included anti-hypertensive drugs diuretics, anticoagulants and other cardiovascular drugs. ${ }^{24}$

\section{Variables associated with occurrence of DRHAs Age}

Age showed significant $(p<0.001)$ association with DRHAs according to univariate analysis but not with multivariate analysis. However, results apparently show that adults are mostly associated with DRHAs. Our results are not supported by few previous results that demonstrate DRHAs were mostly associated with elderly patients. ${ }^{25,26,27}$ The first and foremost reason for our differing results is that large proportion of adult patients was randomly included in our study population. Other reason could probably be the higher degree of non-compliance in adults in comparison to elderly patients. Another plausible explanation is that the appropriate dosage adjustments in geriatric prescriptions as well as the higher number of young adults who are hospitalized at medicine department.

\section{Diabetes mellitus}

Our results implied that diabetes mellitus issignificantly $(p<0.001)$ associated with DRHAs. This is quite interesting to observe that diabetic patients were mostly associated with drug related problems and have more DRHAs. The result could be explained by higher degree of non-compliance $(61.8 \%)$ of diabetic patients. This finding could indicate that health care professionals may be failing to emphasize the importance of dietary and lifestyle changes along with medication and follow up advice.

\section{Hypertension}

Hypertension is one of the factors significantly $(p<0.001)$ associated with DRHAs by both univariate and multivariate analysis. It is observed that most of diabetes mellitus patients are also have HTN as co-morbidity. Similar to diabetic patients, cardiovascular patients are observed to be non-compliance and ADRs are also most commonly associated with the cardiovascular drugs.

\section{Polypharmacy on admission}

Our results of univariate and multivariate analysis indicate polypharmacy $(\mathrm{p}<0.001)$ issignificantly associated with DRHAs. In our study, patients admitted due to DRHAs are relatively high in comparison to patients without polypharmacy in their past medication records. Polypharmacy increases the chance of prescribing drug interactions. Therefore, simpler pharmacotherapy should be considered by physicians to improve the clinical outcome of the patient, to decrease the rate of noncompliance with treatment due to complex dosing schedules, to contribute to safer pharmacotherapy, and to avoid the misuse and prescription of unnecessary drugs. ${ }^{28}$

\section{Preventability}

DRHAs of the patient population were classified into three categories based on their preventability. Drug related hospital admissions with $65.8 \%$ being definitely preventable, $30.2 \%$ were possibly preventable and $4 \%$ were definitely not preventable. Similar to our findings, previous results demonstrate that $7.1 \%$ of hospital admissions result from DRPs, of which $59 \%$ were deemed preventable. ${ }^{29,30}$ On the other hand, A Scottish paper, based on the same methodology, reported that only $13.3 \%$ of admissions were unavoidable. ${ }^{31}$ Several other studies have reported similar findings with 60-70\% of ADRs being classes as preventable., ${ }^{4,32,33,34}$

\section{Summary of key findings}

In summary, our study clearly indicated an incidence of drug related hospital admissions is substantial (17.2\%) and the factors remarkably associated with drug related hospital admissions are age, diabetes mellitus, hypertension and polypharmacy. The major reasons for drug related hospital admissions are non-compliance and adverse drug reactions.

\section{CONCLUSION}

In countries like India where diabetes mellitus prevalence is very high, it is important to increase the awareness among diabetic patients with regard to the importance of therapy and medication adherence. In addition, enhanced collaborative efforts among patients, physicians, pharmacists and caregivers within the community and hospital might reduce the frequency of drug related hospital admissions.

\section{Limitations of the study}

Retrospective study itself has certain inherent problems. For instance, in case of identification of ADRs, authors had to cross verify the appropriateness of data recorded in medical records. Similar is the case for other measurable variables. However, one advantage of retrospective study is that large sample size can be used with great ease depending on the availability of medical records. 


\section{Funding}

The work is not supported by any funding agency.

\section{ACKNOWLEDGEMENT}

We thank Prof. Devala Rao Garikapati, Principal for providing his continuous support during this work. We also thank Director General (Dr. C. Nageswara Rao), Hospital Superintendent and HOD, Dept. of General Medicine (Dr. N. V. Krishna Rao) and Principal (Dr. P. Satyanarayana Murthy) of Dr.Pinnamaneni Siddhartha Institute of Medical Sciences and Research Foundation for granting permission to do Pharm.D Project work and providing the facilities for completion of this work.

\section{Ethical approval}

The study protocol was approved by Institutional Ethics Committee of KVSR Siddhartha College of pharmaceutical sciences institute (Protocol No.: KVSRSCOPS /IEC /2015 /001).

\section{REFERENCES}

1. Easton $\mathrm{KL}$, Chapman $\mathrm{CB}$, Brien JE. Frequency and characteristics of hospital admissions associated with drug-related problems in paediatrics. $\mathrm{Br} \mathrm{J}$ Clin Pharmacol. 2004;57(5):611-5.

2. Hepler CD, Strand LM. Opportunities and responsibilities in pharmaceutical care. Am Hosp Pharm. 1990;47(3):533-43.

3. Roxburgh A, Degenhardt L. Characteristics of drug-related hospital separations in Australia. Drug Alcohol Depend. 2008;92(1-3):149-55.

4. Howard RL, Avery AJ, Howard PD, Partridge M. Investigation into the reasons for preventable drug related admissions to a medical admissions unit: observational study. Qual Saf Health Care. 2003;12(4):280-5.

5. Hallas J, Harvald B, Worm J, Beck-Nielsen J, Gram LF, Grodum E, et al. Drug related hospital admissions. Eur J Clin Pharmacol. 1993;45(3):199-203.

6. McKenney JM, Harrison WL. Drug-related hospital admissions. Am J Hosp 1976; Pharm. 33:792-5.

7. Col N, Fanwle JE, Krinholm P. The role of medication non-compliance and adverse drug reactions in hospitalization of the elderly. Arch Intern Med. 1990;150(4):841-5.

8. Hepler CD. Clinical pharmacy, pharmaceutical care, and the quality of drug therapy. Pharmacotherapy. 2004;24(11):1491-8.

9. Nelson KM, Talbert RL. Drug-related hospital admissions. Pharmacotherapy. 1996;16(4):701-7.

10. Forster AJ, Clark HD, Menard A, Dupuis N, Chernish R, Chandok N, et al. Adverse events among medical patients after discharge from hospital. CMAJ. 2004;170(3):345-9.

11. Hallas J, Harvald B, Gram LF, Grodum E, Brosen K, Haghfelt T, et al. Drug related hospital admissions: the role of definitions and intensity of data collection and the possibility of prevention. J Intern Med. 1990;228;(3):83-90.

12. Winterstein AG, Sauer BC, Helper CD, Poole C. Preventable drug-related hospital admissions. Ann Pharmacother. 2002;36(7-8):1238-48.

13. Zed PZ, Riyad BA, Balen RM, Loewen PS, Hohl CM, Brubacher JR, et al. Incidence, severity and preventability of medication-related visits to the emergency department: a prospective study. CMAJ. 2008;178(12):1563-9.
14. Budnitz DS, Loovegrove MC, Shehab N, Richards CL. Emergency hospitalizations for adverse drug events in older Americans. N Engl J Med. 2011;365(21):2002-12.

15. Patel P, Zed PJ. Drug related visits to the emergency department: how big is the problem. Pharmacotherapy. 2002;22(7):915-23.

16. Juntti-Patinen L, Kuitunen T, Pere P, Neuvonen PJ. Drug-related visits to a district hospital emergency room. Basic Clin Pharmacol Toxicol. 2006;98(2):212-7.

17. Leendertse AJ, Visser D, Egberts AC, Van den Bemt PM. The relationship between study characteristics and the prevalence of medication-related hospitalizations: aliterature review and novel analysis. Drug Saf 201033(3):233-44.

18. Alghamdy MS, Randhawa MA, Al-Wahhas MH, Al-Jumaan MA. Admissions for drug-related problems at the Emergency Department of a University Hospital in the Kingdom of Saudi Arabia. J Family Community Med. 2015;22(1):44-8.

19. Kongkaew C, Hann M, Mandal J, Williams SD, Metcalfe D, Noyce PR, et al. Risk factors for hospital admissions associated with adverse drug events. Pharmacotherapy 2013;33(8)827-37.

20. Tamez-Perez HE, Quintanilla-Flores DL, Rodriguez-Gutierrez R, GonzalezGonzalez JG, Tamez-Pena AL. Steroid hyperglycemia: Prevalence, early detection and therapeutic recommendations: A narrative review. World J Diabetes. 2015;6(8):1073-81.

21. Mathew R, Haque K, Woothipoom W. Acute renal failure induced by contrast medium: steps towards prevention. BMJ 2006;333(7567):539-40.

22. Roughead, EE. The nature and extent of drug related hospitalizations in Australia. J Qual Clin Pract 1999;19(1):19-22.

23. Schneeweiss S, Gottler M, Hasford J, Swoboda W, Hippius M, Hoffmann AK, et al. First results from an intensified monitoring system to estimate drug related hospital admissions. Br J Clin Pharmacol. 2001;52(2):196-200.

24. Miller EFR, Mc Elnay JC, Watt NT, Scott MG, McConnell BJ. Factors affecting the unplanned hospital readmission of elderly patients with cardiovascular disease: a predictive model. Clin Drug Invest. 2001;21(10):705-14.

25. Van der Hooft CS, Dieleman JP, Siemes C, Aarnoudse AJ, Verhamme KM, Stricker $\mathrm{BH}$, et al. Adverse drug reaction-related hospitalisations: a populationbased cohort study. Pharmacoepidemiol Drug Saf. 2008;17(4):365-71.

26. Alexopoulou A, Dourakis SP, Mantzoukis D, Pitsariotis T, Kandyli A, Deutsch M, et al. Adverse drug reactions as a cause of hospital admission: a 6-month experience in a single center in Greece. Eur J Intern Med. 2008;19(7):505-10.

27. Leendertse, AJ, Egberts AC, Stoker LJ, van den Bemt PM. Frequency of and risk factors for preventable medication-related hospital admissions in the Netherlands. Arch Intern Med. 2008;168(17):1890-6.

28. Varallo FR, Capucho HC, Planeta CS, Mastroianni PC. Possible adverse drug events leading to hospital admission in a Brazilian teaching hospital. Clinics. 2014;69(3):163-7.

29. Alghamdy MS, Randhawa MA, Al-Wahhas MH, Al-Jumaan MA. Admissions for drug-related problems at the Emergency Department of a University Hospital in the Kingdom of Saudi Arabia. J Family Community Med. 2015;22(1):44-8.

30. Kongkaew C, Hann M, Mandal J, Williams SD, Metcalfe D, Noyce PR, et al. Risk factors for hospital admissions associated with adverse drug events. Pharmacotherapy 2013;33(8):827-37.

31. Gholami K, Shalviri G. Factors associated with preventability, predictability, and severity of adverse drug reactions. Ann Pharmacother. 1999;33(2):236-40.

32. Hopf $Y$, Watson $M$, Williams $D$. Adverse drug reaction related admissions to a hospital in Scotland. Pharm World Sci. 2008;30(6):854-62.

33. Dartnel JG, Anderson RP, Chohan V, Galbraith KJ, Lyon ME, Nestor PJ, et al. Hospitalisation for adverse events related to drug therapy: incidence, avoid ability and costs. Med J Aust. 1996;164(11):659-62.

34. Beijer HJ, de Blaey CJ. Hospitalisations caused by adverse drug reactions (ADR): a meta-analysis of observational studies. Pharm World Sci. 2002;24(2):46-54. 